\title{
KEWENANGAN PEMERINTAH PROVINSI BALI DALAM PENGAWASAN TERHADAP PRAMUWISATA YANG TIDAK BERLISENSI
}

\author{
Putu Ananda Sari, Ida Ayu Putu Widiati, I Nyoman Sutama \\ Fakultas Hukum Universitas Warmadewa, Denpasar-Bali, Indonesia
}

\begin{abstract}
Abstrak
Penertiban pramuwisata yang tidak memiliki lisensi merupakan kewenangan pemerintah Provinsi Bali melalui Satpol PP sebagai pengawasan seluruh Perda terutama perda pramuwisata. Adapun rumusan masalah dalam penelitian ini Bagaimanakah kewenangan Pemerintah Provinsi Bali dalam melakukan pengawasan terhadap pramuwisata yang tidak memiliki lisensi? Yang kedua apa sanksi terhadap pramuwisata yang tidak berlisensi?. Metode yang dipergunakan dalam penelitian ini emperis yaitu melakukan penelitian lapangan melalui wawancara dan melihat gejala yang ada dalam masyarakat terkait dengan permasalahan. SatPol PP diberikan kewenangan dalam melakukan pengawasan oleh pemerintah bekerja sama dengan polisi pengadilan dan lembaga kepariwisataa dalam sistem penegakkan hokum. Hasil dalam penelitian ini yaitu pemerintah diberikan kewenangan oleh peraturan perundang-undangan yaitu undang-undang Nomor 10 tahun 009 tentang kepariwisataan dan Peraturan daerah Provinsi Bali Nomor 5 Tahun 2016 tentang Pramuwisata pengawasan dilakukan melalui tindakan preventif maupun represif dan dalam sistem penegakkan hokum dan Penerapan sanksi terhadap pramuwisata yang tidak berlisensi yaitu diberikan sanksi denda melalui sidang pengadilan dan pramuwisata yang melakukan pelanggaran akan dikenakan sanksi pelanggaran pariwisata dengan berupa sanksi denda Pelaksanaan dilakukan melalui rahasia para pramuwisata saat menjalankan tugasnya di masing-masing wilayah daya tarik wisata yang ada di Bali lembaga terkait dalam melakukan rahasia pramuwisata dilakukan melalui fungsi kontrol di masing-masing wilayah kerja.
\end{abstract}

Kata Kunci: Kewenangan pemerintah; Pengawasan; Pramuwisata lisensi

\begin{abstract}
Control of unlicensed tour guides is the authority of the Bali provincial government through Civil service police Unit (Satpol PP) as a form of oversight of all regional regulations, especially regional guide regulations. SatPol $P P$ is granted the authority to supervise by the government and cooperate with court police and tourism institutions in the law enforcement system. This study discusses the authority of the Bali Provincial Government in supervising unlicensed tour guides and sanctions against unlicensed tour guides. The method used to achieve these goals is the empirical legal research method, which is to conduct field research through interviews and taking notice of the existing phenomena in society related to the problems being studied. The results of the data analysis show that the government is provided the authority by statutory regulations through Law Number 10 of 009 concerning Tourism and Regional Regulation of the Province of Bali Number 5 of 2016 concerning Tour Guides. Supervision is carried out through preventive and repressive measures and is in the law enforcement system. Sanctions are applied to tour guides who are not licensed by imposing sanctions in the form of fines through court proceedings and tour guides who commit violations will be subject to tourism violations in the form of fines. The implementation is carried out through the secrets of the tour guides when carrying out their duties in each tourism area in Bali. Guiding secrets are executed through the control function in each working area.
\end{abstract}

Keywords: Government Authority; Supervision; Tour Guide; License

\section{PENDAhULUAN}

Pariwisata dan Pulau Bali tidak dapat dipisahkan dimana seni budaya tradisi dan keadaan alam yang menunjang ini menjadi satu kesatuan yang utuh dan tak dapat dipisahkan hal ini membuat pariwisata di Bali mengalami kemajuan yang pesat dan mengungguli daerah yang memiliki potensi 
alam yang lebih indah ketimbang Pulau Bali Perkembangan pariwisata Provinsi Bali sangatlah pesat disebabkan karena berkembangnya peradaban yang dipegaruhi oleh berkembangnya teknologi canggih. Menurut (Hilman, 1987) Perkembangan pariwisata di bali sangat berkembang pesat. tidak menutup kemungkinan menimbulkan adanya Pramuwisata yang tidak berlisensi atau sering disebut dengan Guide Illegal.

Pariwsisata provinsi Bali sebagai pariwisata yang sangat di minati oleh seluruh tamu baik dari manca Negara masupun dari local sendiri. guna memberikan keamanan dan kenyamanan terhadap pramuwisata yang berkunjung di Provinsi Bali peran serta pramuwisata sangatlah penting didalam mengaplikasikan ada budaya dan agama sehingga pramuwisata yang berkunjung di Porovinsi Bali sangat betah. Menariknya Pulau Bali sebagai daerah kunjungan wisata disebabkan kebudayaan yang berbasih hindu serta didukung dengan adapt istiadat budaya social dan politik yang sangat dikenal dengan santun dan keramah-tamahan masyarakat Perkembangan pariwisata di Bali telah dialami sejak nenek moyang hingga saat ini

Sejak dikeluarkannya peraturan mengenai kepariwisataan dan peraturan lainnya sebagai penunjang kegiatan pariwisata dapat menunjang dan meningkatnya arus kunjungan wisatawan ke Bali hal tersebut dapat kita lihat banyaknya sarana dan prasarana pariwisata sebagai penunjang kehidupan masyarakat Bali sangat berpengaruh atas kunjungan wisatawan seperti seni kerajinan seni kebudayaan dan lain- laina. Dalam ketentuan Perda Pramuwisata, pramuwisata di wilayah hukum Provinsi Bali diwajibkan memiliki Sertifikat Lulus Uji Pengetahuan Budaya Bali sebagai bukti kelayakan kompetensi untuk menerangkan Kebudayaan Bali kepada wisatawan, sehingga dapat menghindari kesalahan pahaman atas budaya Bali yang berujung pada pelecehan kebudayaan Bali (Eka \& Yanti, 2020).

Ada beberapa peneliti terdahulu melakukan penelitian yang relevan dengan penelitian ini yang pertama, (Hidayat, 2018) Dalam penelitiannya menyimpulka bahwa dalam pengelolaan bidang pariwisata di Bali semua pihak harus mengacu pada Pergub. Karena Pergub ini mengikat dan berlaku di semua elemen pariwisata yang ada di Provinsi Bali sehingga hal ini meningkatkan pengelolaan pariwisata yang baik yan mampu memberikan kenyamanan kepada para wisatawan. Penelitian yang kedua dilakukan oleh (Wijaya, 2015) dalam penelitiannya menyatakan kedepan pariwisata Bali harus berbenah diri dalam menerima dampak luas, yang dapat menjadi ancaman bagi eksistensi pariwisata. Selajutmya (Suryawati, 2018) menyatakan ada beberapa beberapa startegi yang menjamin keberlangsungan pariwisata Bali adalah strategi yang mendukung keberlanjutan politik dan keamanan yang mendukung kenyamanan wisatawan, keberlanjutan ekonomi masyarakat Bali, keberlanjutan lingkungan (ekologis), serta keberlanjutan sosial dan budaya masyarakat Bali. Berdasarkan identifikasi masalah di atas adapun tujuan dalam penelitian ini untuk menjelaskan kewenangan Pemerintah Provinsi Bali dalam melakukan pengawasan terhadap pramuwisata yang tidak memiliki lisensi, Selanjutnya menjelaskan penerapan sanksi terhadap pramuwisata yang tidak berlisensi.

\section{METODE DAN PEMBAHASAN}

Jenis penelitian yang digunakn ini yaitu secara emperis artinya melakukan Penelitian lapangan melalui wawancara melihat kejadian yang sebenarnya yang ada di masyarakat terkait dengan permasalahan (Kadir, 2004). Jenis penelitian sebagai bentuk didalama mendapatkan data yang ada kaitannya dengan permasalahan dengan melakukan pendekatan di lapangan melalui wawancara dengan para pihak yang memahami permasalahan sehingga hasil penelitian yang didapatkan menjadi lebih akurat dan dapat dipertanggungjawabkan secara ilmiah. Pendekatan yang digunakan adalah pendekatan peraturan perundang-undangann yaitu pendekatan dengan menggunakan legislasi dan regulasi (Marzuki, 2005). Data yang digunakan adalah data primer diperoleh langsung ke masyarakat atau kelapangan melalui wawancara dengan pihak yang memahami permasalahan dan melakukan penelitian berupa kepustakaan majalah media elektronik dan peraturan perundang-undangan (Soekanto, 2013). Pengumpulan data menggunakan teknik wawancara dimana antara pewawancara dengan yang diajak wawancara berhadapan secara langsung dengan memberikan pertanyaan sesuai dengan permasalahan untuk memperoleh data yang otentik tentang Implementasi Kewenangan Satuan Polisi Pamong Praja dalam penegakkan Peraturan Daerah Provinsi Bali mengacu pada peraturan perundang- undangan yang berlaku terkait dengan pramuwisata yaitu Perdana Nomor 5 Tahun 2016. Analisis data menggunakan teknik deskriftif kualitatif disamping sifat data yang 
dikumpulkan berjumlah besar mudah dikualifikasi kedalam kategori- kategori data yang terkumpul terdiri aneka gejala yang dapat diukur dengan angka-angka hubungan antara variabel sangat jelas pengambilan sampel dilakukan sangat cermat dan teliti serta pengumpulan data mengunakan kuisioneri (Parikesit dan Trisandi 2003 No 16 / VI).

\section{HASIL DAN PEMBAHASAN}

\section{Kewenangan Pemerintah Provinsi Bali dalam Melakukan Pengawasan terhadap Pramuwisata yang Tidak Memiliki Lisensi}

Polisi Pamong Praja diberikan mandate atas kewenangan pemerintah Provinsi Bali dalam penegakkan Perda Pramuwisata Bali dalam melakukan pengawasan terhadap pramuwisata yang sedang menjalankan tugasnya Pemerintah Provinsi Bali memberikan kewenangan sepenuhnya dalam mengawal dan pengawasan melalui SatPol PP dan jajaran yang terkait Pengawsan dilakukan secara kontinyu dengan bekerja sama dengan komponen-komponen terkait didalamnya yaitu Himpunan Pariwisata Provinsi Bali DPD HPI Bali Komisariat DPD HPI Kepolisian Kejaksaan dan Kehakiman Tujuan dari pemerintah melakukan pengawasan agar pramuwisata dapat menjalankan tugasnya sesuai dengan ketentuan dalam undang-undang. Kekwenangan pemerintah Provinsi Bali dalam melakukan pengawasan selalu mengedapankan keamanan dan kenyamanan bagi pariwisata yang berkunjung di Provinsi Bali Yang dijadikan landasan hukum pemerintah memberikan pengawasan terhadap pramuwisata Apabila dalam pengawasan pemerintah terhadap pramuwisata yang tidak memiliki lisensi di saat menjalankan tugasnya maka akan dilakukan upaya pembinaan dan peringatan disamping memberikan pelatihan mengenai pariwisata dan memberikan pendidikan adat agama dan budaya terkait dengan pariwisata (James, 1994).

Dalam menjalankan kewenangan Polisi Pamong Praja (SatPol PP) dibantu oleh Pengurus Himpinan Pariwisata Bali ( DPD HPI ) Bali dan dibantu oleh beberapa anggota dari DPD HPI Divisi Domestik (divisi Bahasa Indonesia) Pramuwisata yang paling dominant atau paling banyak adalah Pramuwisata yang berbahasa Indonesia dalam aturan pramuwisata seroang pramuwisata yang sedang menjalankan tugasnya harus menggunakan lisensi sesuai dengan bahasanya Dalam melakukan pengawasan di lapangan atau melakukan sidak di lapangan banyak pramuwisata yang tidak menggunakan lisensi bahkan pramuwisata yang belum pernah melakukan training melakukan pekerjaan sebagai pramuwisata sehingga adapt dan budaya yang dijelaskan tidak sesuai dengan adapt dan budaya Bali. Pramuwisata yang menjalankan tugasnya wajib menggunakan kartu tanda anggota sesuai dengan bahasa yang di miliki dan menggunakan pakaian adapt Bali kecuali pramuwisata melakukan perjalanan bermain wisata air Apabila dalam pengasan didapatkan pramuwisata dalam menjalankan tugasnya memiliki lisensi yang sudah mati maka diarahkan atau dianjurkan untuk melakukan perpanjangan lisensi dengan disertai pendidilan dan pelatihan mengenai budaya.

Sebagai dasar Pengaturan Perlindungan hokum Berdasarkan Peratutan Daerah Nomor 5 tahun 2016 tentang Pramuwisata sebagaimana telah diuraikan diatas mengenai tugas-tugas pramuwisata dalam menjalankan profesinya memiliki fungsi dan peran yang sangat penting dalam industri pariwisata adapun fungsi pramuwisata dalam industri pariwisata adalah sebagai berikut

a. Menemani mengantarkan wisatawan ke kawasan obyek dan daya tarik wisata

b. Memberikan informasi Kawasan Obyek dan Daya Tarik Wisata

c. Memasarkan Produk Wisata

d. Memberikan pelayanan dengan Prilaku Budaya Daerah

e. Memberikan pelayanan dengan Prilaku Budaya Bangs

\section{Penerapan Sanksi terhadap Pramuwisata yang Tidak Berlisensi}

Penergakkan Peraturan Pemerintah Provinsi Bali di bidang kepariwisataan wewenang sepenuhnya dilakukan oleh pemerintah Provinsi Bali dengan memberikan mandate kepada SatPol PP dalam memberikan perlindungan hukum terhadap wisatawan yang berkunjung ke Bali agar wisatawan yang sedang melakukan perjalanan ke Daya Tarik Wisata mendapatkan informasi yang benar sesuai dengan adat dan budaya Bali dan berbagai budaya yang lainnya. Agar wisatawan betah berkunjung di Bali dan akan berampak pada daerah asalnya atau Negara asalnya menceritakan atau memberi tahukan tentang masalah Balisecara utuh Agar wisatawan yang berkunjung di Bali 
menjadi aman Pemerintah Provinsi Bali mengeluarkan aturan yang mengatur mengenai Pariwisata salah satunya Perda Pramuwisata Bali.

Sesuai dengan surat tugas team sudah dijadwalkan melakukan penegakkan hukum tentang Pramuwisata yaitu Perda Nomor 5 Tahun 2016 tentang Pramuwisata di Kabupaten/Kota se-Bali secara bergilir sesuai dengan skala prioritas Proses penegakkan Peraturan Daerah ini dapat dikatakan hampir sama di semua kabupaten dan kota di Bali karena dasar hukumnya sama yaitu Keputusan Gubernur Bali Nomor 11 Tahun 2004 tentang Pedoman Operasional Penyidik Pegawai Negeri Sipil Daerah. Dalam penegakkan Peraturan Daerah Team akan bergerak kelapangan ke lokasi yang menjadi target operasi operasi penegakkan akan menyasar salah satu obyek wisata di kabupaten/kota di Bali karena disini akan banyak ditemukan pramuwisata yang sedang memandu wisatawan Lamanya waktu operasi tergantung situasi dan kondisi tetapi biasanya tidak lebih dari 2 (dua) jam Setelah sampai di lapangan team dikumpulkan untuk mendapat pengarahan dari ketua team atau yang dituakan tentang pembagian tugas siapa berbuat apa dan diberi wejangan untuk tetap sabar dan jaga sopan-santun di lapangan dalam menghadapi pelanggar yang terkadang marah dan emosi karena kena sidak

Apabila salah satunya ada yang melanggar Pramuwisata diberi surat panggilan menghadap kepada Penyidik Pegawai Negeri Sipil untuk disidik dan diproses lebih lanjut sampai dengan tingkat peradilan Penyidik meminta barang bukti berupa Kartu Tanda Penduduk atau Kartu Tanda Pengenal Pramuwisata tergantung pelanggaran yang dilakukan dan barang bukti yang dibawa si pelanggar kemudian diberikan surat tanda penerimaan barang Penyidik juga membuat laporan kejadian sebagai bahan dalam penyidikan Pramuwisata dipanggil ke Kantor Satuan Polisi Pamong Praja Kota/Kabupaten sesuai dengan tanggal surat paggilan dan jam yang telah ditentukan untuk menghadap kepada Penyidik Pegawai Negeri Sipil yang menangani guna pemeriksaan sebagai tersangka pelanggaran Peraturan Daerah Nomor 5 Tahun 2016 tentang Pramuwisata Setelah operasi penegakkan berjalan 2 (dua) jam ketua team menghentikan operasi kegiatan dilanjutkan dengan pendataan hasil operasi Berapa orang melanggar tanpa KTPP berapa orang melanggar KTPP-nya masa berlakunya sudah habis dan berapa orang pramuwisata tanpa pakaian adat Bali Terakhir akan jelas terlihat dari blangko pendataan berapa jumlah Pramuwisata yang diperiksa seluruhnya yang melanggar berapa dan yang tidak melanggar berapa jumlahnya

Apabila pramuwisata sedang menjalankan tugasnya maka SatPol PP melakukan penyelidikan dan penyidikan Penyidikan adalah tahap dimulainya tindakan-tindakan hukum oleh Penyidik Pegawai Negeri Sipil Daerah yang membatasi hak-hak asasi seseorang yang dianggap bertanggungjawab atas terjadinya pelanggaran pidana di bidang Pramuwisata tindakan-tindakan hukum yang dimaksud adalah seluruh tindakan yang menurut Undang-undang menjadi wewenang Penyidik Pegawai Negeri Sipil yang dapat dikenakan kepada seseorang tersangka dalam proses penyidikan Penyidikan dimulai dengan dikeluarkannya surat perintah penyidikan yang ditandatangani oleh Kepala Satuan Polisi Pamong Praja Setelah Penyidik Pegawai Negeri Sipil menerima surat perintah Penyidik harus memberikan surat pemberitahuan dimulainya penyidikan (SPDP) kepada Jaksa Penuntut Umum melalui penyidik Polri. Penyidik juga dapat meminta bantuan polisi untuk membawa dengan paksa tersangka atau saksi kehadapannya apabila tersangka atau saksi tetap tidak mau datang setelah diberi surat panggilan kedua dan ketiga untuk itu penyidik harus membuat surat permintaan bantuan kepada polisi (Situmorang, 1989).

Penyidik Pegawai Negeri Sipil juga memberitahukan secara tertulis kepada tersangka bahwa berkas perkaranya sudah dilimpahkan kepada Jaksa Penuntut Umum Berkas yang diserahkan ke Penuntut Umum akan diteliti oleh Jaksa bila masih ada yang perlu dilengkapi dan disempurnakan maka Jaksa Penuntut Umum akan meminta perbaikan dengan mengembalikan berkas perkara kepada penyidik atau istilah P 19 setelah di perbaiki oleh penyidik berkas itu dikirim kembali kepada Jaksa apabila berkas dianggap betul atau sempurna Jaksa Penuntut Umum mengatakan berkas sudah betul atau P 21. Biasanya hakim memutus perkara pelanggaran Peraturan Daerah Provinsi Bali Nomor 5 Tahun 2016 tentang Pramuwisata bervariasi tergantung hakim dan sikap tersangka selama persidangan dengan hukuman denda sebesar Rp 1000000-(satu juta rupiah) subsider 7 (tujuh) hari pidana kurungan dan membayar ongkos perkara Rp 5000-(lima ribu rupiah) Dengan denda yang cukup besar diharapkan para pramuwisata tidak lagi mengulangi perbuatannya lagi dan untuk menumbuhkan efek jera bagi si pelanggar maupun pramuwisata lainnya 


\section{SIMPULAN DAN SARAN}

\section{Simpulan}

Berdasarkan pembahasan dan hasil penelitian maka dapat ditarik kesimpulan yaitu:

1. Kewenangan Pemerintah Provinsi Bali dalam melakukan pengawasan terhadap pramuwisata yang tidak memiliki lisensii dimana pemerintah diberikan kewenangan oleh peraturan perundang-undangan yaitu undang-undang Nomor 10 tahun 2009 tentang kepariwisataan dan Peraturan daerah Provinsi Bali Nomor 5 tahun 2016 tentang Pramuwisata pengawasan dilakukan melalui tindakan preventif maupun represif dan dalam sistem penegakkan hukum

2. Penerapan sanksi terhadap pramuwisata yang tidak berlisensi yaitu diberikan sanksi denda melalui sidang pengadilan dan pramuwisata yang tidak berlisensi tidak diperkanankan untuk mengantar rombongan atau tami sebagai bentuk perlindungan hukum yang diberikan kepada wisatawan yang berkunjung ke Bali adalah melalui kewenangan Satuan Polisi Pamong Praja dalam Penegakkan Peraturan Daerah Provinsi Bali Nomor 5 Tahun 2016 tentang Pramuwisata di Bali adalah melakukan sidak di masing-masing daya tarik wisata dengan bekerja sama dengan instansi terkait yaitu Kejaksaan Kehakiman Pramuwisata melalui koordinasi kontrol Sidak/atau sweeping silakukan sesuai dengan amanah Perda Nomor 5 Tahun 2016 apabila ditemukan pramuwisata yang melakukan pelanggaran maka dapat dilakukan penindakan di tempat dan/atau dilakukan penyelidikan dan penyidikan oleh PPNS sampai pada proses persidangan bentuk perlindungan yang lainnya memberikan rasa aman dan nyaman terhadap wisatawan yang berkunjung ke Bali Pramuwisata agar dapat memberikan informasi yang jelas dan tegas kepada wisatawan baik di luar daya tarik wisata maupun disaat berada di daya tarik wisata

\section{Saran}

Berdasarkan uraian diatas penulis menyarankan sebagai berikut

1. Diharapkan Kepala Pemerintah dalam hal ini Kota/Kabupaten Aparatur Negara terkait dan Satuan Polisi Pamong Praja melakukan koordinasi dan fungsi kontrol terhadap pelanggaran Perda Nomor 5 Tahun 2016 karena selama ini kurangnya koordinasi sehigga banyaknya pelanggaran yang dilakukan oleh pramuwisata dalam mengantarkan wisatawan berlibur di Bali.

2. Diharapkan Ketua DPD HPI Bali Ketua Komisariat di masing- masing Divisi melakukan pembinaan kepada pramuwisata guna meningkatkan kedisiplinan dan kepatuhan terhadap para wisatawan.

\section{DAFTAR PUSTAKA}

Eka, A. A. I., \& Yanti, K. (2020). Peranan Pramuwisata dan Pemerintah dalam Mencegah Pelecehan Kepariwisataan Budaya Bali. 14(2), 77-86.

Hidayat, S. (2018). Model Pengembangan Pramuwisata Olahraga dalam Bisnis Pariwisata di Provinsi Bali. 5(1), 8-16.

Hilman, H. (1987). Hukum Kekerabatan Adat. Fajar Agung.

James, S. J. (1994). Pariwisata Indonesia Siasat Ekonomi dan Rekayasa Kebudayaan. Kanisius.

Kadir, A. (2004). Hukum dan Penelitian Hukum. PT Citra Aditya Bakti.

Marzuki, P. M. (2005). Penelitian Hukum. Prenada Media.

Situmorang, V. (1989). Dasar Dasar Hukum Administrasi Negara. Bina Aksara.

Soekanto, S. (2013). Penelitian Hukum Normatif. Rajawali Pers.

Suryawati, I. G. A. A. (2018). Strategi Pengembangan Pariwisata Bali Berkelanjutan Menghadapi Pasar Bebas Asean (afta). Jurnal Mitra Manajemen Online, 2(6), 680-692.

Wijaya, K. (2015). Masa Depan Pariwisata Bali ( Perspektif Permasalahan dan Solusinya ). Riset Ekonomi Dan Manajemen, 15(1), 118-135. 